DOI: $10.35218 /$ armca.2020.1.06

\title{
Stylistic Study of Gowijeh Qaleh's Rock-Cut Tomb from Maragheh
}

\author{
Saeid Sattarnejad ${ }^{*}$, Samad Parvin $^{* *} \&$ Maryam Mastalizadeh $^{* * *}$
}

\begin{abstract}
Rock architecture has a long history in Iran and all over the world, and many climatic, defensive, cultural factors have led to the emergence of architectural examples of this type. The chronology and usage of these works have always been discussed after the discovery of the rock works from Western Iran from the $19^{\text {th }}$ century onwards. On the one hand, it can be said that the creators of these works have left a rather vague footprint of their time, making difficult the possibility of offering accurate and precise chronology and explaining usage for researchers and interested readers. On the other hand, due to the lack of knowledge and awareness of the beliefs of ancient people, some scholars have been mistaken in explaining the use and even the chronology of these works and sometimes, they presented different uses and chronologies for these works. Accordingly, such a mistake was made by a number of researchers in the city of Maragheh while explaining the use of Gowijeh Qaleh's rock tomb by the use of water storage. For this purpose, this article examined Gowijeh Qaleh's rock-cut tomb from an analytical perspective. Therefore, this work can be more confidently considered as a part of the first millennium $B C$, and it is referred to the culture of Urartu.
\end{abstract}

Keywords: Gowijeh Qaleh, User, Urartu, Rock Tombs

\section{Introduction}

Gowijeh Qaleh's site, with its architectural and rock cutting work and arching of its joint, is located in the village of Ghouri-chay in Seraji district of Maragheh, 48 kilometers East, away from Maragheh ${ }^{1}$, and the north-east of Miandoab. It is also situated 10 kilometers away from the South of Maragheh road to Zahak castle and it is one of the branches of Ghouri-chay

\footnotetext{
* PhD student of the Archaeology of Islamic Periods, University of Mohaghegh Ardabili, Faculty of Literature and Human Sciences, saeidsattarnejad@ yahoo.com

${ }^{* *}$ Graduate of Archaeology, University of Mohaghegh Ardabili, Faculty of Literature and Human Sciences, arjaan1370@gmail.com

${ }^{* * *} \mathrm{PhD}$ student of the Archaeology of Islamic Periods, University of Mazandaran, Faculty of Arts and Architecture, mastalizadeh@gmail.com

${ }^{1}$ Boris Piotrovsky, Urartu Civilization, 2004, p. 372.
} 
in the same rural area ${ }^{2}$. It is located at 37 degrees, 13 minutes North, the meridian $46^{\circ}$ and 42 minutes West of the Eastern side. ${ }^{3}$ The village of Ghouri-chay is located in the west of Hashtrood province, and it is limited by Hashtrood province in the North, by Ajirloy of Maragheh in the South, by Maragheh province in the West, and to Charuymaq in the East. ${ }^{4}$

Gowijeh Qaleh's rock tomb was discovered and introduced by a German archeologist named Wolfram Kleiss in 1973. In the same year, he published a fairly complete report about this monument in the Amine Magazine, attributing it to the culture of Urartu. The technique of cutting the rocks of this unique rock tomb in Maragheh region did not remain unnoticed, it attracted the attention of many Maragheh scholars, and it opened up many theories about its use and its occasional chronology. However, the unknown aspects of rock tomb and the lack of reference to previous studies have always led to controversial issues of archeological studies and the history of Maragheh until today regarding the chronology and explanation of its use. Studying Gowijeh Qaleh's rock-cut tomb is a challenge, it represents the best platform for chronology; due to having the most historical evidence in comparison with other rock-cut tombs of Maragheh city, it is a great study object. In other words, the chronology and explanation of the use of Gowijeh Qaleh's rock-cut tomb is important because it can be used as a solution to reveal the regional history of Maragheh in the first millennium BC. In this paper, a comprehensive analysis has been made by analyzing the data of this rock tom, by comparing proofs with other similar historical works. To accomplish this, the background of the tradition of building rock tomb has been studied in the area and Gowijeh Qaleh's rock tomb has been studied and compared with other Urartu branches in terms of stylistics.

\section{Research question}

The most important question launched in this article is related to its plan and stylistic study. Which one of these characteristics is comparable with the identified Urartian's rock tomb?

\section{Research Methodology}

The research method in this paper is based on field activities, which include field visits from a large number of rock-cut tomb architectural collections in different parts of Maragheh city. Moreover, library studies have been carried out on Urartu rock tombs in the West Azarbaijan Province and

\footnotetext{
${ }^{2}$ Karim Hajizadeh, Investigation of Urartu Establishment Patterns in the North-West of Iran, 1996, p.151.

${ }^{3}$ Saeid Sattar Nejad, Archeological Study of Architecture in Maragheh, 2017, p. 84.

${ }^{4}$ Behrouz Khamachi, The culture of East Azerbaijani Geography, 1992, p. 420.
} 
the Anatolian region. It should be noted that the library studies in this field have also been complementary to field activities.

\section{Significance of the study}

Considering the special circumstances and restrictions of the history of Maragheh city in the first millennium BC on the one hand, and the lack of detailed study of the effects of the rock-cut tomb of Maragheh province on the other hand, we have made this native architectural research having a limited place in Maragheh's archeological studies. Therefore, the article can be regarded as the basis for the researchers of Maragheh, in order to get familiarized with the traditions of burial in the region during the first millennium BC, and it can also increase their desire to study the field of rock architecture in the region.

\section{History of Studies}

Kleiss was the first person who had made the first reference to the site of Gowijeh Qaleh castle in 1973. He considered this work to be belong to Urartian taxpayers ${ }^{5}$. In 1981, Van Hulsteyn referred to the site in his doctoral dissertation. Piotrovsky also mistakenly referred to this work as Gowjor Qaleh $^{6}$. Later in the solar year of 1996, Dr. Karim Hajizadeh introduced the castle with the theme of the Investigation of Urartian Settlement Patterns in his thesis of postgraduate course. Of course, his only source was Kleiss's article. $^{7}$ Among the researchers in the city of Maragheh, various people have written about this castle including Alireza Pashaei, a postgraduate student in the field of archeology, Islamic Azad University, Abhar Branch. Also, two papers at the Sahand-Khodajo's Regional Conferences and the International Conference on Tehran's rock-cut Architecture can be added to this collection. ${ }^{8}$ Tohid Hemati Aroghun at the Sahand-Khodayoo Conference, and Hossein Naseri Some studied this site in their two articles. In the solar year of 2017, Saeid Sattar Nejad studied the collection, while investigating the architecture of the city of Maragheh".

\section{Rock-cut tomb}

Rock-cut architecture is a special type of architecture in which spaces are created consciously and specifically in rocks and mountains. Due to the

\footnotetext{
${ }^{5}$ Wolfram Kleiss, Urartu Architecture, 1970.

${ }^{6}$ Boris Piotrovsky, op. cit., p. 372.

${ }^{7}$ Karim Hajizadeh, op. cit.

${ }^{8}$ Alireza Pashaei, Archeological Research of the Gowijeh Qaleh's Castle, 2015

${ }^{9}$ Saeid Sattar Nejad, op. cit.
} 
cost, time, and expertise that the architect uses for this particular type of architecture, its use seems very important. Accordingly, a large part of rockcut architecture has ritual and religious uses, and it relates to the history of religions. In some religions and nations, this type of architecture has been used as a rock tomb, ossuary, crypt, stone caverns and so on for burial. Rock tomb is said to be called "stone tombs" which were usually cut into a cliff or sloping rock face in mountains ${ }^{10}$. In the first millennium $\mathrm{BC}$, we see the almost extensive use of rock-cut architecture for the construction of a tomb in the area. In this respect, the kingdom of Urartu has been preceded, and it seems that making rock tomb in Iran is rooted in the Uratian tradition ${ }^{11}$. There are many rock tombs in the Eastern Anatolia, which preceded the territory of the Uratian kingdom. The history of Urartu has shown that they used chambers or rocks as tombs or basements ${ }^{12}$. As a matter of fact, it may be possible to divide rock tombs into two types of single-room and multiroom rock tombs with a general assessment of their plan. However, it seems that the oldest created rock spaces are related to the central regions of Asia Minor and the era of the Hittite Empire. This tradition was continued by Urartians, Phrygians, Cilicia, and Lycian in the first millennium $\mathrm{BC}^{13}$. Osmanoğlu believed that the origin of the Urartu graves should be considered from the tomb of the Hourri tribes in Carchemish.

\section{Introduction and stylistics of Gowijeh Qaleh's rock-cut tomb}

The Gowijeh's rock tomb has been built in the North-Eastern side, towards the center of the castle and inside the castle fortress, where it can best protect it. Access to the tomb is possible, as in the case of Urartian, through two sets of stone stairs ${ }^{14}$. The use of stairs was something common in Urartian rock tombs. Sangar and Varahram rock tomb can be included in those works (Image 1). An archaeological report has been published on the existence of 30 stairs ${ }^{15}$. The use of the one-way staircase in Limestone Mountains, opposite the Sangar Village, establishes the link between religious stone building, probably special for god of khalid on the mountain, and large rock tombs at the foot of the mountain ${ }^{16}$. It seems that the use of a staircase in the façade of the Orarutian's rock tombs, in addition to access to the tombs, may have had a spiritual role. Accordingly, the existence of a

\footnotetext{
${ }^{10}$ Gholamali Hatam, Rock tombs in the Median period, 2003, p. 106.

${ }^{11}$ Kazem Mollazadeh, Med Archeology, 2015, pp. 324-325.

${ }^{12}$ Bahman Kargar, Urartu's tomb in West Azerbaijan, 1990, p. 53.

13 Kazem Mollazadeh, op. cit., p. 324.

${ }^{14}$ Hossein Naseri Somae et all, Introduction and Survey of the Ancient Tomb of Gowijeh Qaleh in Maragheh, 2015, p. 36

${ }^{15}$ Wolfram Kleiss, op. cit., pp.289-312.

16 Bahman Kargar, op. cit., p. 55.
} 
staircase in the Orarutian's rock tombs indicates that they were repeatedly used for burials ${ }^{17}$ (Images 2 and 3). A set of staircases consists of 6 stone stairs connecting the rock tomb to the North-East of the castle and the second set is over 30 stone stairs (Figure 4) extending from the East and the center of the castle to the mouth of the rock tomb.

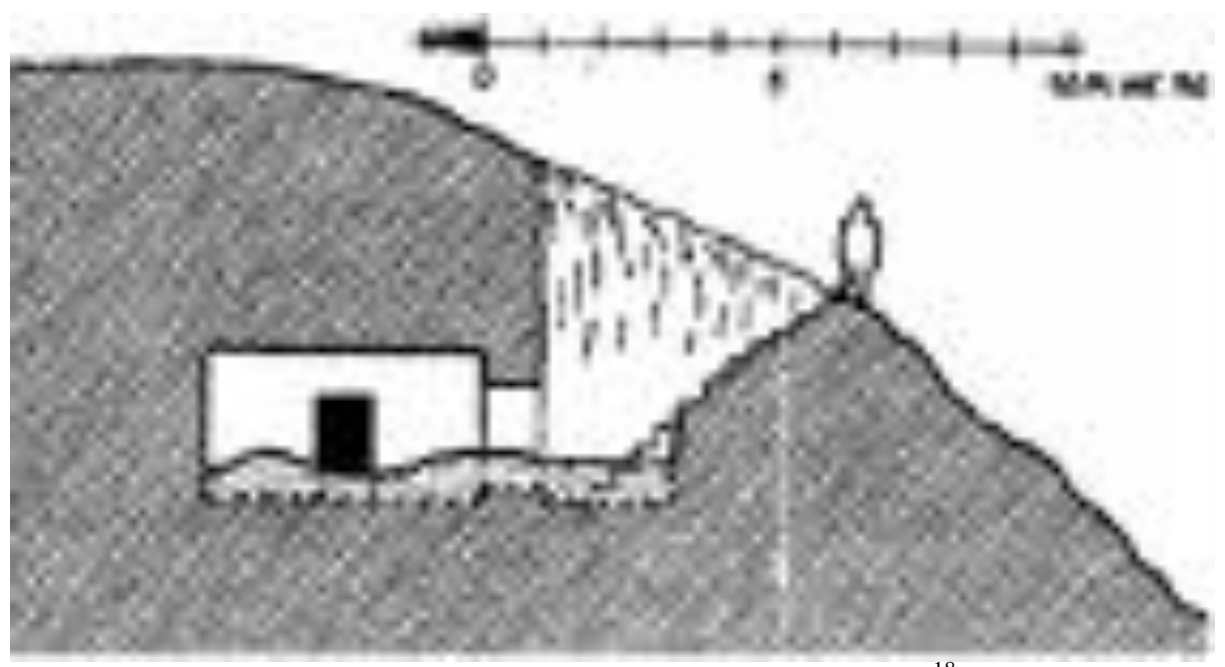

Fig. 1 The section of the rock tomb of Varahram ${ }^{18}$

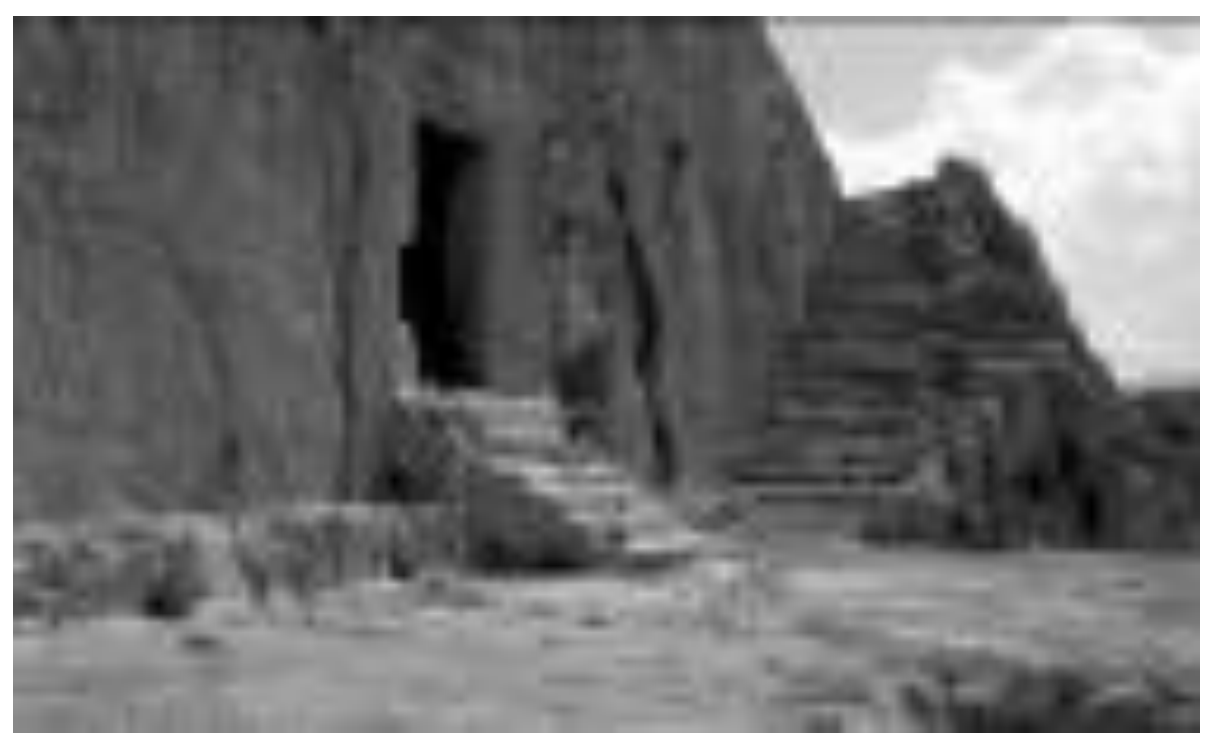

Fig. 2 Van Castle

${ }^{17}$ Kazem Mollazadeh, op. cit., p. 352.

${ }^{18}$ Boris Piotrovsky, op. cit., p. 357. 


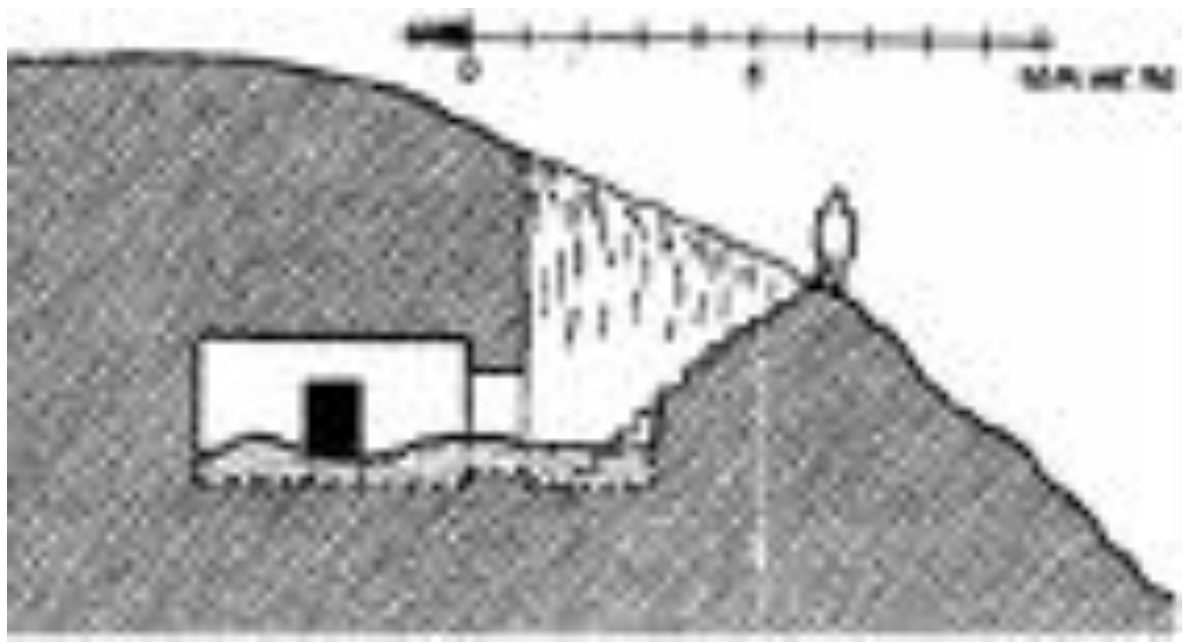

Fig. 3 Section of rock tomb of Van Castle

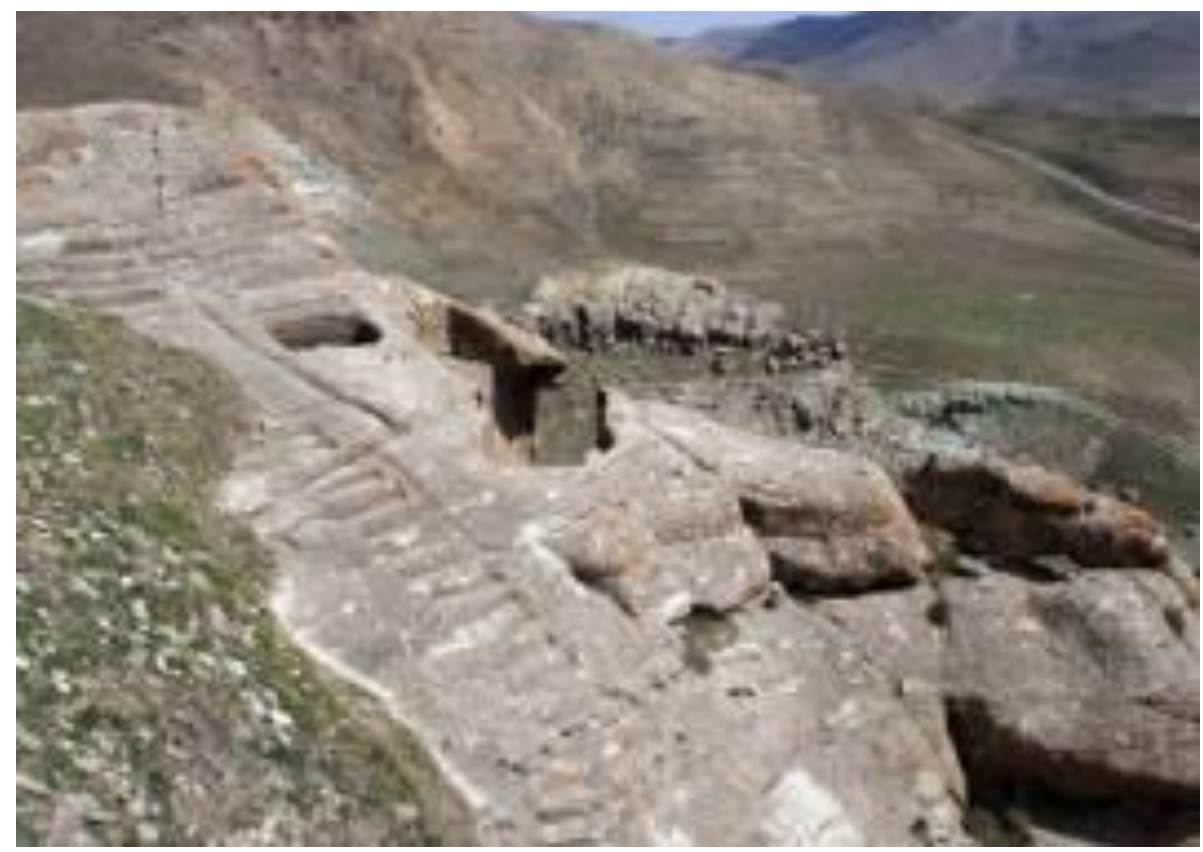

Fig. 4 Stairs used in Gowijeh Qaleh 
The tomb consists of two parts. The first part is open having a width of $220 \times 115 \mathrm{~cm}$ and a depth of $260 \mathrm{~cm}$, and it has a frame. In the Urantian tombs of Azerbaijan, the use of a staircase or a small quadrangle space in front of the tomb is considered as an entrance gate or port. Similar to the quadrangle port, the staircase is available in Qarniyahrokh and Ismail agha. There is also a sample of combinations of stairs attached to the tomb chamber by the quadrangle port in the Urartian's Poldasht tomb ${ }^{19}$. You can enter the small port $(110 \times 110$ centimeters $)$ from the first part to the second part. The original space is approximately $340 \times 340 \mathrm{~cm}$ in a square shape, extended in two steps from the West and North to the joining rooms. The height of these spaces is $160 \mathrm{~cm}$ and the roofs are flat, having arches in angles. ${ }^{20}$

From the rocky architectural works up to the Achaemenid period, flat and right-angled surfaces with no curved lines can be seen in the port and roofs coating, but in the Parthian period, these coatings or coverings have been shaped into curves. The reason for changing the form of architectural elements from flat to curve can be attributed to the advancement of Iranians architecture in the creation of arches covering by using more conventional materials without the need for more durable wood. This change can be seen dramatically from this period on. The design of the rock tomb is flat. The Mannaean rock tomb of Fakhrigah has flat covering and it is right-angled and free-cutting ${ }^{21}$. The roof of Ismaili Agha's tomb had been carved roughly and irregularly, belonging to the $7^{\text {th }}$ century $\mathrm{AD}$, based on the obtained clays. Varahram's rock tomb located in Shutlo, West Azarbaijan, and Sheytanabad's rock tomb located $10 \mathrm{~km}$ North of Miandoab have a flat cover $^{22}$; Sangsar's rock tomb located $9 \mathrm{~km}$ North from the Maku River has also a flat cover. The rock tomb and squared room of Gowijeh Qaleh have a flat covering as well. ${ }^{23}$ Accordingly, rock-cut spaces, particularly the rock tombs of the Urartu and the remaining Mannaean, have flat roofs. The follow of the creation of flat roof is an example that is equally observed in all of them, without any exception ${ }^{24}$.

\footnotetext{
${ }^{19}$ Bahman Kargar, op. cit., p. 55-56.

${ }^{20}$ Hossein Naseri Somae et all, op. cit., p.36.

${ }^{21}$ Kazem Mollazadeh, op. cit., p. 362.

${ }^{22}$ Karim Hajizadeh, op. cit.

${ }^{23}$ Wolfram Kleiss, op. cit., pp. 33-34.

${ }^{24}$ Bahman Kargar, op. cit., p. 55.
} 


\begin{tabular}{|l|l|l|l|}
\hline section & period & location & \multicolumn{1}{|c|}{ name } \\
\hline urartu & $\begin{array}{l}\text { Mowijeh } \\
\text { Qaleh }\end{array}$ \\
\hline & manna & mahabad & fahkrika \\
\hline & Urartu & Urmia & Ismail Aqa \\
\hline & & & \\
\hline & & & \\
\hline
\end{tabular}

Table 1 Section of rock tombs with flat covering

The Western space and then the Northern space were carved after the carving of the main square space and the reason for this is that the pit which was being constructed in the Northern space as a grave was left abandoned and incomplete. In the center of the Western space, there is a rectangular pit with a length of $168 \times 115 \mathrm{~cm}$ and a depth of $80 \mathrm{~cm}$ whose usag has been recognized as a pit. The Northern space is a rectangle with a size of $440 \times$ $210 \mathrm{~cm}$, in the center of which a hole measuring 120x120 cm was created. Only 10 centimeters of its depth were cut and then abandoned incomplete for unknown reasons, thus its carvings remained unfinished. Considering the plan, the elements and the location of rock tomb, its comparison with other Urartian's rock tomb, especially the tomb of Ismail Agha, Varahram and Oshnavieh in the West Azerbaijan, it can be concluded that the rock tomb of 
Gowijeh Qaleh is a kind of connected and continuous single-room rocky tombs and has been imitated from the Urantian plan of rock tombs. In ancient times, the place and type of tombs showed the social status of the buried ${ }^{25}$. This tomb has been reported as the most eastern Urartian tomb in the northwest of $\operatorname{Iran}^{26}$.

\section{Conclusion}

In this study, by examining the plan's form, the presence of the stairs and the flat roof of the rock tomb and generally, from the stylistic view, this tomb is considered to have a single-room plan, a flat roof, and stairs. From this point of view, this tomb is comparable to Van Castle, Ismail-Agha, Varahram and so on. Accordingly, although Wolfram Kleiss in his report describes and refers to the presence of pottery in the culture of Urartu in the structure of Gowijeh Qaleh, surely he does not consider that the site belongs to the culture of Urartu. He believes that due to pale works and a few potteries, the Urartian index of this site may belong to the Urartian taxpayers who learned the staircase technique and the rock tomb from their own Urantia conquerors. The stylistic study of this tomb has an undeniable similarity to the identified Urartian rock tomb. Accordingly, by an archaeological look into the category of burial and religious beliefs, it can be said that the Gowijeh Qaleh's rock tomb is the manifestation of the religious beliefs of the inhabitants of the region in the first millennium BC. The belief is only part of the Urartu burial patterns. This rock tomb is still the most eastern Urartu rock tomb in Iran.

\section{Appendix}

In Turkish, the letter "G" is pronounced "g" only at the beginning of the word, and it pronounced both "G" or "Y" in the middle and the end of the word. For example, Agri (crooked) is also pronounced Erie (Dictionary of Shahmiri, 2016: 10). Accordingly, the correct pronunciation of the castle is "Gowgja Qala".

Gowgja $\Longrightarrow$ Gowijeh

\section{Bibliography:}

Hajizadeh, Karim, Investigation of Urartu Establishment Patterns in the NorthWest of Iran, Master's Degree of Anthropology, Tarbiat Modares University of Tehran, 1996.

\footnotetext{
${ }^{25}$ Hossein Naseri Somae et all, op. cit., p. 37.

${ }^{26}$ Karim Hajizadeh, op. cit., pp. 151-152.
} 
Hatam, Gholamali, Rock tombs in the Median period, Art Quarterly, No. 52, Fall and Winter, pp. 106-118, 2003.

Kargar, Bahman, Urartu's tomb in West Azerbaijan, Archeological and history Journal, No. 2, pp. 57-55,1990.

Khamachi, Behrouz, The culture of East Azerbaijani Geography, Tehran: Soroush Publication, 1992.

Kleiss, Wolfram, Urartu architecture, translated by Gholamali Homayoon, Journal of Historical Review, No. 4, 1970.

Mollazadeh, Kazem, Med Archeology, Tehran: Samt Publication, 2015.

Naseri Somae, Hossein; Pashaei, Alireza; Sa'adati, Mohsen, Introduction and Survey of the Ancient Tomb of Gowijeh Qaleh in Maragheh, Journal of the Archeologist Message, vol. 11, No. 22, pp. 46-33,2015.

Pashaei, Alireza, Archeological Research of the Gowijeh Qaleh's castle, Master's Degree in Anthropology, Islamic Azad University, Abhar Branch (Not Published), 2015.

Piotrovsky, Boris, Urartu Civilization, Translated by Hamid Khatib Shahidi, Tehran: Andishehye-no Publication, 2004.

Sattar Nejad, Saeid, Archeological Study of Architecture in Maragheh, Master degree in Archeology, University of Mohaghegh Ardabil, 2017. 